\section{A experiência de ter um filho com deficiência mental: narrativas de mães}

\author{
Raising children with mental disabilities: mothers' \\ narratives
}

\section{Instituto Fernandes Figueira, Fundação Oswaldo Cruz, Rio de Janeiro, Brasil. \\ Correspondência O. M. Bastos \\ Instituto Fernandes Figueira Fundação Oswaldo Cruz. Rua General Dionísio 20, apto. 602, Rio de Janeiro, $R J$ 22271-050, Brasil. olgab@iff.fiocruz.br}

\begin{abstract}
Technical advances in neonatology have increased the life expectancy of children with serious health problems. Many of these children experience developmental delay (mental disability) and require special care. The family must adapt to better provide for the child's needs. This study aimed to identify mothers' reactions and the obstacles they face to obtain what they consider the best treatment for their children. The study methodology was based on analysis of the mothers' narratives, drawing on medical anthropology and linguistics. The most typical plots in the narratives showed the impact of the diagnosis and the search for means to adapt to the child's care, as well as the difficulties encountered in the public health system to obtain what the mothers considered adequate care. The value ascribed to characters in the support network showed the importance of such support in these situations.
\end{abstract}

Disabled Children; Mental Health; Personal Narratives
Olga Maria Bastos 1

Suely Ferreira Deslandes 1

\section{Introdução}

O avanço tecnológico neonatal tem contribuído para a sobrevida de bebês de muito baixo peso e para os que têm doenças mais complexas, e isto repercute em um aumento considerável da população com deficiência mental. Pelo Censo Demográfico 2000 (Instituto Brasileiro de Geografia e Estatística; http://www.ibge.gov.br) existem no Brasil 24,5 milhões de pessoas com deficiência ( $14,5 \%$ da população brasileira). Neste grupo, 2.848.684 de pessoas têm deficiência mental, que correspondem a $11,6 \%$ do total de indivíduos com algum tipo de deficiência. Entretanto, parece que o aumento desta população não se refletiu no desenvolvimento de recursos e mecanismos sociais para lidar com estas crianças e suas famílias 1 .

A atenção às pessoas com deficiência mental constitui um desafio para a organização dos serviços públicos de saúde, que ainda apresenta reduzida oferta de serviços, baixa cobertura, difícil acesso, descontinuidade de atendimento, entre outros problemas estruturais do Sistema Único de Saúde (SUS), que se agudizam sobremaneira na atenção a este grupo ${ }^{2}$. Embora nem sempre se constitua como uma doença crônica, a deficiência mental configura demandas de cuidados que se estenderão ao longo de toda uma vida, repercutindo nas dinâmicas, identidades e papéis familiares 3,4 . 
O impacto para os pais quando o filho apresenta algum problema de saúde que necessite cuidados constantes, do nascimento ao longo de toda sua vida, desafia também a Saúde Pública no sentido de promoção da integralidade, uma vez que estas crianças demandam atenção intersetorial e estes cuidadores também necessitam de atenção para que possam sustentar seu papel protetivo ${ }^{5}$. Para as famílias e, especialmente para as mães, as conseqüências de ter um filho nestas condições são ainda maiores, uma vez que culturalmente a elas compete o cuidado da prole. Este impacto também se relaciona a frustrações de expectativas sobre o bebê que está para nascer. Desde a gestação são definidos parâmetros de "normalidade", e este nascimento anunciado é endoculturado, sendo o futuro da criança projetado segundo referentes do que se entende como próprio ao papel das novas gerações ${ }^{6}$. Quando esta criança necessita de cuidados especiais, os pais geralmente se sentem frustrados e despreparados para cuidar dela. Para Klaus et al. 7 o nascimento de um bebê fora dos padrões de normalidade, então definidos científica e culturalmente, é considerado assustador para os envolvidos, sendo sobrepostas as fases de reação sócio-psíquica, tais como o luto, a adaptação e o aprendizado de novas formas de cuidar. Os autores apontam que a resolução da discrepância entre a imagem idealizada do filho e a imagem real, tarefa imposta à constituição de parentalidade, fica mais difícil na situação da deficiência.

Ter um filho com deficiência exemplifica o que Goffman ${ }^{8}$ vai denominar, no campo do interacionismo social, como uma ruptura da representação do "eu", onde a projeção de um certo conceito de si é vista pelos demais atores como incompatível com os padrões de reconhecimento. Assim, pode acontecer de as posições anteriores "tornarem-se insustentáveis e os participantes encontrarem-se sem uma linha de ação estabelecida" 8 (p. 222). Conseqüentemente, as "concepções de si mesmo em torno das quais são construídas sua personalidade podem ficar desacreditadas" 8 (p. 223) Neste sentido, os esforços de reconstituição das identidades como ator (fabricante de impressões de si aos outros) e como personagem (imagem moral digna de crédito) serão engendradas.

Este trabalho explora este cunho teórico, tendo como objetivo analisar que significados os pais atribuíram ao diagnóstico ao saberem que seus filhos tinham deficiência mental, um problema de saúde que necessitará de cuidados especiais, assim como que artifícios foram, segundo eles, utilizados para poderem elaborar a nova condição. Além disto, também nos interessou conhecer como se deu o percurso terapêutico e de reabilitação, revelando o papel dos diversos atores da rede social e instituições como facilitadores, ou não, dos problemas enfrentados.

\section{Metodologia}

A constatação de um problema de saúde de um filho que vá demandar cuidados constantes funciona como um ponto de virada ou de mudança, ou seja, como um divisor entre "o antes" e "o depois" do evento, motivando a elaboração de narrativas 9 . As narrativas, via de regra, giram em torno de situações e experiências, e mesmo que apresentem um assunto geral, demonstram a forma como o narrador lidou com a situação e como atualiza sua ação na história ${ }^{10}$. Contudo, os significados atribuídos aos eventos refletem expectativas e compreensões provenientes da participação em um mundo moral e social específico ${ }^{11}$.

Uma vez que a experiência individual do sofrimento é diretamente inacessível aos demais, as narrativas funcionam como importantes mediadoras entre a experiência e as representações culturais, fazendo emergir o sujeito como o personagem central e não sua patologia 12,13. Ao tecer uma narrativa sobre enfermidade ou sofrimento se reconstrói pelo discurso uma reordenação inteligível da desordem instaurada. Neste sentido, como afirma Kleinman ${ }^{3}$, a narrativa dá um contexto e domestica a experiência ao colocá-la numa referência da cultura. Narrativas de doenças têm muito em comum com as narrativas ficcionais, dado que também possuem um ou mais enredos; têm indeterminação e abertura; são influenciadas pela motivação dos participantes e se constituem de eventos abertos à re-interpretação 14 .

Deste modo, utilizamos como método a análise de narrativas, cuja abordagem metodológica tem como principais referências disciplinares a sociologia, a lingüística e a antropologia.

Para o antropólogo Byron-Good 12 (p. 139) a narrativa é “...uma forma na qual a experiência é representada e recontada, na qual os eventos são apresentados como tendo uma ordem coerente $e$ significativa; na qual atividades e eventos são descritos conjuntamente às experiências, sendo associados com os significados que lhes emprestam as pessoas envolvidas".

O narrador oferece ao ouvinte comentários morais, demonstrando o modo como as coisas são, como deveriam ser, e principalmente, o tipo de pessoa que ele pretende mostrar que é 10 . O relato de uma narrativa deve ser compreendido como uma forma de interação, pois sua enunciação está relacionada ao momento em que está 
sendo contada, à situação que se apresenta, assim como também estará na dependência das reações de quem é o ouvinte 15 .

Para analisar o conteúdo das narrativas foram incorporadas algumas orientações, destacandose as de Thompson 16 e as de Byron-Good 12 .

Thompson 16, ao se referir às formas simbólicas presentes nos discursos, propõe um referencial metodológico aplicável às narrativas. Este autor apresenta três fases para a investigação dos textos que foram adotados por nós: (1) a reconstrução do contexto sócio-histórico em que as narrativas foram produzidas; (2) a análise formal ou discursiva, que permite desvendar as construções simbólicas que circulam nos campos sociais; (3) a interpretação/re-interpretação.

Para conhecer minimamente o contexto da construção das narrativas utilizamos dados pessoais objetivos, tais como das condições de vida e dos recursos disponíveis e utilizados pelas famílias, assim como aspectos que surgiram durante a entrevista e que permitiram a compreensão dos contextos interacionais e discursivos de onde provinham tais narrativas.

Dentre os métodos de análise formal propostos por Thompson 16, utilizamos a análise de estrutura de narrativas da sócio-lingüística de Labov 17 , que foi a base para a organização do acervo da pesquisa e que considera como narrativas os relatos que tenham pelo menos dois enunciados narrativos (ou orações) em seqüência temporal. Nelas, procuramos identificar o sumário (uma ou duas frases que dão o resumo e podem conter o ponto da história), a orientação (identificação do tempo, do lugar, das pessoas ou da situação narrada), a ação complicadora (que identifica o que aconteceu), a coda (cláusulas livres que podem conter observações ou mostrar efeitos do acontecimento ao narrador) e a avaliação (que indica o ponto da narrativa). Dentre as múltiplas formas de análise da estrutura narrativa 18 , a proposta de Labov 17 não prioriza a organização temporal das narrativas, mas sua dimensão avaliativa, permitindo antever os efeitos morais que busca produzir.

Reafirmando a proposta laboviana, Linde 19 concebe uma função social à narrativa e, desta forma, considera a avaliação como sua parte mais importante, por representar o recurso que o narrador utiliza para transmitir o ponto da história ou mesmo para mostrar porque ela é importante. É o que indica ao interlocutor como ele deve entender o significado da seqüência de eventos e o tipo de resposta que o narrador deseja obter. Esta etapa da análise possibilita a identificação da avaliação moral que foi feita, revelando particularidades do narrador, que tipo de pessoa está se apresentando.
A partir da adoção das orientações de ByronGood 12 buscamos identificar os enredos típicos. Identificamos os enredos sobre as experiências ao receber o diagnóstico da deficiência mental do filho e sobre o percurso terapêutico de reabilitação. Para este autor, enredo é o que ordena o relato de forma significativa, articulando as experiências e os eventos de tal forma que componham uma história.

As análises das narrativas também nos auxiliaram a desvendar as representações sociais presentes nos enredos, nas ações narrativas e na avaliação, assim como podem promover a compreensão do modo como as representações foram enunciadas, atualizadas ou transformadas pelos atores sociais 20. Segundo Alves 21, a experiência do adoecer revela aspectos sociais e cognitivos incorporados nas representações individuais, que estão sendo continuamente reconstruídas pela própria mudança da doença com o tempo e pelo confronto com diferentes diagnósticos e discursos familiares e sociais.

Nos procedimentos de análise, em cada um dos enredos das narrativas sobre a reação ao diagnóstico e reabilitação localizamos os personagens presentes, a ação propriamente dita e a avaliação que o narrador faz de si mesmo e dos indivíduos que surgiram nas narrativas. Depois da análise de cada entrevista, fizemos a leitura transversal da totalidade do acervo, identificando os enredos típicos de cada bloco.

A terceira e última fase, proposta por Thompson 16, no processo de interpretação/re-interpretação, as inferências interpretativas foram debatidas à luz da literatura pesquisada.

Foram realizadas 12 entrevistas, sendo que sete com mães de adolescentes do sexo feminino e cinco com mães de adolescentes do sexo masculino, atendidos nos ambulatórios de genética ou de neurologia de uma unidade de saúde de nível terciário. As entrevistadas, com os respectivos filhos na adolescência, já acumularam experiência suficiente em suas passagens pelas várias unidades de saúde e de educação e já construíram sucessivas narrativas do impacto do diagnóstico e da trajetória terapêutica. O número de entrevistas realizadas também permitiu atingir o ponto de saturação necessário à identificação de enredos recorrentes.

A pesquisa foi aprovada por um Comitê de Ética em Pesquisa da unidade, reconhecido pelo Comitê Nacional de Ética em Pesquisa. 


\section{Resultados e discussão}

As entrevistadas e o contexto de produção das narrativas

As entrevistadas tinham os filhos sendo atendidos pela rede pública de saúde e de educação do município ou do Estado do Rio de Janeiro, Brasil. Neste grupo a renda familiar variou de 1 a 10 salários mínimos (SM), mas a maior parte se situava entre 2 a 6 SM. Predominaram as famílias com dois filhos. A idade dos adolescentes era de 11 a 19 anos, majoritariamente na faixa etária de 12 a 14 anos.

Moradoras de bairros do subúrbio e da zona oeste, as narradoras pertenciam a famílias que dependiam quase que integralmente dos serviços públicos e todas revelaram um longo itinerário entre serviços de saúde e alguns de educação para o atendimento do filho.

Diferenças entre a ocupação profissional das narradoras ou o número de filhos não mostraram relação com o tipo de narrativa construída. Por outro lado, a religiosidade, presente em quase todas as entrevistas, demonstra ter influenciado nos desfechos de resignação à situação da deficiência, constante nos enredos.

Estas depoentes carregam também uma longa vivência de interlocução com os discursos dos agentes da saúde, incorporando jargões e expressões biomédicas, ampliando e dando complexidade ao seu campo interpretacional.

As narrativas também foram produzidas num contexto específico da vida familiar, no momento em que seus filhos vivenciam a puberdade. A influência dos discursos sociais sobre adolescência se fez notar, ora buscando-se identificações quanto ao comportamento do filho como capaz de integrar grupos sociais etários, ora reconhecendo invariáveis distâncias de uma "adolescência normal”. Por fim, o contexto imediato de produção destas narrativas se deu pela interlocução de uma médica que entrevistava estas mães, usuárias de um serviço de saúde. Como se daria em qualquer narrativa, o tipo de ouvinte, a quem se dirige a história, também influencia na seleção e apresentação de fatos, enunciados e signos que comporão a história. Entende-se que não se trata, entretanto, de saber fidedignamente o que seria a "verdadeira narrativa”, mas analisar as lógicas culturais aí subjacentes, os valores e significados compartilhados coletivamente 13 .
A constatação da deficiência do filho: narrativas de redefinição identitária

“Olha, eu para falar uma verdade, (Sumário)

Eu não sabia nem o que era [síndrome de Down]. (Sumário)

Depois, aí o médico falando, (Ação Complicadora)

Alguém falou (...) a criança assim. (Ação Complicadora)

Mas é filho. (Avaliação)

Deus me deu assim, eu vou aceitar do jeito que ele é" (Coda/Avaliação).

Este foi um enredo típico de nosso acervo sobre o impacto da notícia. Inicialmente revelando a falta de compreensão com o acontecido, seguida da busca de explicação com vistas à reordenação simbólica da desordem instituída, e finalmente a re-significação identitária. Como na narrativa acima, os enredos se iniciam sempre com enunciado sobre a surpresa e o intenso sofrimento com a notícia de que o filho tinha um problema de saúde que teria como conseqüência a deficiência mental.

Segundo Mannoni 22, o filho com deficiência dificilmente poderá fazer parte das expectativas maternas, dificultando uma afirmação positiva de sua identidade pessoal, como mulher e também como mãe. Paixão 23, ao estudar as representações sociais e a síndrome de Down, observou que algumas representações são associadas ao estigma e à discriminação da deficiência, e que a depreciação da criança é sentida pela mãe como uma depreciação de si própria.

Os personagens comuns listados nos enredos ligados ao diagnóstico configuravam como coadjuvantes (médicos, marido, outros filhos e outros parentes), sendo o filho com deficiência o protagonista destas histórias, já que suas próprias vidas passariam a girar em função dele, que necessitaria de cuidados constantes e intensos.

A elaboração do enredo das narrativas de mães que tiveram o diagnóstico logo ao nascimento do filho foram semelhantes. Inicialmente, mesmo com o médico enunciando o fato, elas não conseguiam incorporá-lo de imediato. Certamente não se tratava apenas de não compreender as explicações técnicas ou por uma negação ao fato, ou mesmo pela associação de ambos. $\mathrm{O}$ que se depreende é que estes relatos causavam tal desordem e ruptura de expectativas que demandariam uma re-elaboração dos pais através de mediações coletivas ao longo de certo tempo, sejam por familiares ou pela confirmação de outros especialistas.

Algumas narrativas puseram em evidência a redefinição identitária do filho após o diagnóstico médico. As mães mencionaram a elaboração 
simbólica da perda do filho "normal". Tudo se modificaria a partir de então, e lidar com esta nova situação se mostraria tarefa complexa, agravando-se ainda mais quando eram atendidas por profissionais que não proveram acolhimento ou não demonstraram maior sensibilidade ao tratar a questão.

"Você quer o começo do Carlos? (Sumário)

O Carlos, quando ele fez quatro anos ele não falava. (Orientação)

...e eu dei de cara com um monte de ignorantes. (Avaliação)

...Aí ela olhou bem na minha cara. (Ação Complicadora)

Olhou para a cara do Carlos. (Ação Complicadora)

E disse assim:-Esse menino é um mongolóide! (Ação Complicadora)

E aí (...) quando eu saí, eu já saí chorando de dentro da sala" (Coda).

Ao iniciar a narrativa com "o começo do Carlos”, esta mãe fala sobre um novo reconhecimento do menino, agora de um filho com uma definição pública de "anormalidade". Ao ser redefinido socialmente, aquela criança (e sua mãe) começaria(m) uma nova trajetória de identidades familiares eculturais. Estas narrativas reafirmamo estigma e senso de vergonha atribuídos aos sujeitos e familiares portadores de deficiência mental assim como de outras doenças crônicas que envolvem deformações ou condições consideradas vexatórias (como a colostomia, por exemplo) 3 . Kleinman ${ }^{3}$, resgatando a perspectiva de Goffman ${ }^{8}$, vai lembrar que o estigma associado a certas enfermidades levaria a introjeção de uma identidade danificada, desacreditada. $\mathrm{O}$ autor cita a China como um exemplo de sociedade em que o estigma da doença mental é tão poderoso que envolve todos os familiares (inclusive seus ancestrais remotos) ${ }^{3}$. Este aspecto de atribuições causais aos vínculos consangüíneos é singular para o quadro de deficiência mental, dado que se relaciona à formação do bebê. Assim, provavelmente mais enfaticamente que na doença mental, será fortemente associada ao imaginário da hereditariedade, ao papel genético dos pais e às condições da gravidez.

Para uma melhor compreensão da situação, muitas mães procuraram justificativas para o acontecido. Em uma tentativa de se eximirem da provável e implícita culpa a elas atribuída, apresentaram o estranhamento que mesmo diante de um filho desejado isto pudesse ter acontecido.

"Me pegou assim de surpresa, (Coda)

Porque como primeira filha...(Orientação)

Tiveumagravidezsaudável,então...(Avaliação)

Não estava esperando que eu tivesse ela assim, com esse problema" (Ação Complicadora).
Neste trecho esta mãe se preocupou em narrar que nada indicava que teria um "filho com problemas", mostrando-se perplexa que os fatores que pareceu identificar como protetores - "como primeira filha" (indicando ter sido desejada), e uma gravidez sem problemas - não tivessem sido suficientes para impedir o que aconteceu.

As situações que surgiram nas entrevistas são também pontuadas por Klaus \& Kennell 24; eles mencionam o trabalho de Prugh, de 1953, que observou que a culpa foi freqüentemente detectada quando as mães constatavam alguma "anormalidade" nos filhos. Elas, assim como as mães desta pesquisa, se perguntavam o que haviam feito ou deixado de fazer durante a gestação que pudesse ter afetado o bebê. Para Cavalcante 25, em uma cultura em que o papel paterno é menos valorizado, a mãe se julga a única responsável por ter gerado um filho com deficiência.

Como visto na citação que abre esta seção, os enredos geralmente finalizam com declarações de resignação e de amor incondicional ao filho, condizentes com as expectativas e comportamentos apreendidos culturalmente na condição de ser mãe. A fé em Deus e a sua vontade, muito além de um simples instrumento de apoio, foi utilizada por algumas mães para explicar o acontecido e facilitar a conformação frente ao fato, assim com também para ganhar forças para o enfrentamento das adversidades. De acordo com Waldman et al. 26 , a religião parece influenciar a família a uma maior aceitação do filho com deficiência mental. $\mathrm{O}$ autor observou que os pais religiosos, assim como as mães no nosso acervo, tenderiam a ver seus filhos nesta situação mais como uma oportunidade de testemunho de fé ou como uma estratégia de um plano geral de Deus.

Em seqüência ao tópico da aceitação gradativa do diagnóstico os enredos passaram a versar sobre as mudanças nas rotinas familiares.

"Tive que é (...) modificar a minha vida, não é? (Avaliação/Coda)

No que diz a (...) parei de trabalhar. (Sumário)

...né, para que eu fizesse os tratamentos com ele. (Ação Complicadora)

...para ajudar no desenvolvimento dela, né. (Ação Complicadora)

...tem meu marido (...) a gente teve que..." (Ação Complicadora)

Como descreve Aramayo 27, os pais terão que cumprir novas tarefas, além das usuais, a fim de atender às necessidades de tratamento e reabilitação deste filho. Em muitas entrevistas isto ficou claro, especialmente quando falavam sobre os vários médicos a serem consultados e os exames que precisavam ser feitos, o que demandava muito tempo disponível. Esta mo- 
dificação do cotidiano tornou-se evidente em várias narrativas.

As narradoras, com diferentes intensidades, construíram uma auto-avaliação heróica, considerando que não mediram esforços para dar o melhor aos filhos, demarcando o testemunho de um sacrifício intenso, a fim de melhor contribuir para o desenvolvimento deles. Waldman et al. 26 observaram que esta sobrecarga materna seria um dos achados mais consistentes nas pesquisas envolvendo famílias que têm filho com deficiência mental. Rabelo et al. 13 confirmam as profundas mudanças que as mães fazem em suas vidas profissionais e pessoais para cuidar de um filho com doença mental.

Como confirmam os estudos de Garro \& Mattingly 11 sobre narrativas de mães de crianças com enfermidades crônicas, estas narradoras se utilizam de forte poder retórico, enfatizando sua grande abnegação para cuidar dos filhos. A partir daí, começaram a re-escrever suas próprias histórias de vida. Os projetos que tinham para o futuro foram modificados em uma adaptação radical a essa nova realidade. Estas narrativas tratam, portanto, da construção de duas novas identidades, da criança, agora "portadora de necessidades especiais" e da mãe, que heroicamente se dedicará quase que integralmente ao cuidado e melhora do estado de saúde do filho. A partir de então elas passam a narrar sobre os percursos institucionais para o alcance destes objetivos.

\section{Reabilitação: aprendendo a lidar com os desafios}

Segundo o que se preconiza atualmente, o processo de reabilitação da criança ou do adolescente com deficiência mental, se constitui em um conjunto de atividades que tem por objetivo fornecer o apoio para o alcance de uma maior autonomia, respeitando-se os limites impostos pela deficiência e favorecendo sua integração social 28.

Os enredos sobre o percurso terapêutico e de reabilitação versaram, principalmente, sobre a insatisfação com os resultados obtidos neste sentido. Numa temporalidade dinâmica, as narrativas colocam em evidência as dificuldades iniciais de acesso a terapêuticas e serviços.

O descontentamento muitas vezes era imputado a atendimentos inadequados na área da saúde e da educação, como colocado emblematicamente nas narrativas a seguir.

“Ah! Olha eu (...) eu não estou nem pensando no futuro dele. (Orientação/Coda)

Porque nenhum remédio está dando certo para ele. (Ação Complicadora/Avaliação)
Ele não tem noção de nada, do perigo... (Ação Complicadora/Avaliação)

Ano passado ele já repetiu a progressão. (Ação Complicadora)

Ele não teve melhora nenhuma" (Avaliação)

"Como era uma clinicazinha... (Avaliação)

Ela falava assim: (Orientação)

- Ah, tá na hora de aumentar o remédio da Milene.(Ação Complicadora)

Mas ela nem examinava a Milene, nem pedia outro eletro... (Ação Complicadora)

Aí comecei a achar aquilo estranho. (Sumário)

Eu falei: - Chega, eu não vou mais fazer nada disto. (Ação Complicadora)

Até que um dia, um rapaz lá do trabalho. (Orientação)

Ele me indicou o neurologista, o Dr. Pedro" (Avaliação)".

Estas narrativas expressam a insatisfação com a atenção recebida, já que as narradoras não perceberam ações que favorecessem uma maior autonomia, inclusão social ou melhora clínica.

No primeiro enredo, característico em nosso acervo, apareceu a preocupação com o futuro do filho. Nas demais seqüências narrativas, se referiam à falta de resolutividade da atenção recebida, tanto pelos profissionais da saúde quanto pelos da educação.

Tais enredos são produzidos à luz do convívio com uma rede de serviços que pouco contribuiu para o desenvolvimento mais satisfatório destes adolescentes, de re-interpretações das informações recebidas e de expectativas fantasiosas sobre um desenvolvimento dos filhos, incompatível com suas possibilidades orgânicas.

$\mathrm{O}$ aspecto interpessoal se destacou nos enredos das avaliações críticas que apareceram nas narrativas com relação à falta de sensibilidade dos médicos ou professores na atenção às pessoas com deficiência. Para as mães, os profissionais deveriam ter maior preparo e tato para lidar com a situação.

Contudo, como pode se ver no segundo enredo, puderam ser encontrados médicos "bons" e "maus" ou professores "atenciosos" ou não. Portanto, as entrevistadas não colocaram em julgamento a categoria profissional, mas sim a qualidade do encontro que os profissionais estabeleceram com elas. Esta relação é discutida por Rocha et al. 29, ao avaliarem a qualidade da assistência médica sob a ótica dos usuários. Eles se reportam a Sommers, um autor que considera que uma assistência é satisfatória quando é dada ao paciente a oportunidade de formular perguntas, de receber explicações sobre o problema em questão, e que também é capaz de levá-lo a 
compreender a intervenção médica recomendada ${ }^{29}$. Mishler 30 reforça a importância deste "ato relacional”, e destaca a importância de ouvir o paciente, pois estas narrativas serão essenciais para a melhor condução terapêutica.

As mães também narraram sua busca constante por uma atenção idealizada como a mais condizente para as necessidades dos filhos. Muitas de suas histórias foram relativas às dificuldades encontradas, tais como exames que não eram feitos pelo SUS e medicamentos considerados importantes para o tratamento não disponibilizados pelas farmácias da rede pública, prejudicando a reabilitação de seus filhos. Além disto, relataram a inexistência de atendimento por uma equipe multidisciplinar, fundamental para o desenvolvimento de toda a potencialidade das pessoas com deficiência mental.

As narrativas sobre educação não apareceram de forma tão contundente quanto as sobre a saúde, talvez pelo fato de a entrevistadora ser médica. Entretanto, foi reconhecida a sua importância no processo de reabilitação, apresentando maior visibilidade na adolescência, talvez relacionada com as expectativas que os pais têm do futuro dos filhos. A criança que não sabe ler e escrever tem um significado muito diferente de um adolescente que ainda não conseguiu ser alfabetizado. Na adolescência esta dificuldade ficaria mais evidente, pois as mudanças no corpo decorrentes das manifestações puberais tornam mais visíveis as diferenças intelectuais, colocando-os mais distantes dos da mesma idade, sem deficiência.

As narrativas apontavam nestes adolescentes alguns atributos que atestariam o seu potencial para o aprendizado (como por exemplo, saber dançar, saber se maquiar, reconhecer locais e pessoas). Desta forma, a dificuldade em aprender a ler sugeria que na escola não existiria o estímulo necessário para o desenvolvimento de suas potencialidades, como explicitado no seguinte trecho narrativo.

"É por isso que eu fico assim: (Coda)

Pô, ele sabe dançar um forró demais, ele bota... (Ação Complicadora)

Tem gente que fica de boca aberta com ele dançando. (Ação Complicadora)

Porque Bruno não tem inteli... (Ação Complicadora)

Por que que o juízo só é ruim para o estudo? (Sumário)

É isso que me (...) fica assim encafifando, entendeu?" (Avaliação).

Nota-se que a narradora abandona no meio da enunciação a expressão inteligência, um termo tão associado ao senso comum a padrões objetivos de performance (como o QI), substi- tuindo-o pelo de "juízo", evocando então capacidades mais amplas de aprendizagem.

As insatisfações com a educação estiveram presentes, principalmente, nas falas das mães dos adolescentes do sexo masculino, que avaliaram que a escola não cumpria seu papel na alfabetização e em outras competências que resultassem em maior autonomia. Este assunto raramente foi trazido à discussão pelas mães das adolescentes, sugerindo diferente posicionamento de gênero.

Assim como para a sociedade global, a alfabetização foi tida pelas entrevistadas como um passaporte que seus filhos teriam para o exercício da cidadania, considerando-se que o efetivo direito dos indivíduos estaria atrelado à autonomia que ela pode conferir. A procura de empregos e o acesso a informações, com a conseqüente possibilidade de escolhas, estão entre os itens que se encontram comprometidos em um indivíduo analfabeto. Aramayo 27, em contrapartida, defende que para a socialização, a dificuldade de comunicação por problema de linguagem, leitura e escrita teria menor magnitude que a ausência de determinadas competências, tais como o uso de transporte público e o manejo de dinheiro.

Os enredos denunciam uma vivência distanciada do que se preconiza como patamares de inclusão internacionalmente estabelecidos. Os que versam sobre educação nos permitem supor que não estariam sendo respeitados os compromissos firmados na Declaração de Salamanca ${ }^{31}$, que pressupõe uma "educação para todos", incluindo a urgência de prover educação para pessoas com deficiências, dentro do sistema regular de ensino - a educação inclusiva. Para Vivarta 32 a inclusão é uma conquista no campo dos direitos humanos, que visa dignificar toda a diversidade humana.

Silva 33 alerta quanto à tarefa prioritária da educação especial, que de acordo com a Constituição Federal do Brasil é de elevar o nível de competência técnica das pessoas com deficiência, em uma luta para a inclusão social. A autora também defende que para que a inclusão social efetivamente ocorra é fundamental, entre outros critérios, que haja a aceitação das diferenças individuais, a valorização de cada ser humano e o aprendizado de conviver com a diversidade.

No hiato entre os discursos sociais de garantia de direitos e de inclusão, as narrativas relataram outras estratégias, em que a ajuda mútua familiar, da vizinhança e mesmo de alguns profissionais, funcionaram como elos de proteção, evitando a solidão, as ameaças econômicas e o desespero. 
Rede social de apoio e sua importância para o cuidado

“Aí, juntou a família toda, para juntar aquele dinheiro todo [para comprar um medicamento muito caro]. (Ação Complicadora)

Cheguei aqui ele [outro médico] estava aí. Aí na mesma hora ele deu um remédio. (Coda)

Que eu (...) meu marido, correu também para (...) conseguir" (Coda).

O tema da rede social de apoio emergiu espontaneamente nas narrativas. Não chegam a constituir enredos próprios, mas atravessam transversalmente aqueles sobre reabilitação. $\mathrm{O}$ que pôde ser observado é que a rede de suporte social, quando atuante, interferiu melhorando as condições da família, seja do ponto de vista econômico e afetivo, ou de ambos.

Vários foram os personagens evocados como colaboradores na resolução de empecilhos encontrados no cotidiano. Estavam presentes, de forma coadjuvante, os agentes das instituições da saúde e da educação, e, como protagonistas, familiares, amigos e os cônjuges.

No Brasil, e particularmente para o grupo social de que as entrevistadas fazem parte, constata-se uma maior vulnerabilidade, que pode levar as famílias a grandes dificuldades para a reabilitação de seus filhos. Vários autores 34,35,36 analisam que nas últimas décadas tem-se explorado a importância do apoio social na recuperação de saúde, que facilita o enfrentamento dos problemas e a diminuição dos efeitos negativos de situações estressantes, contribuindo para o bem-estar geral.

Como se sabe, o apoio emocional e o suporte financeiro, obtidos através das práticas relacionadas à fé ou pela rede composta por amigos, parentes ou na vizinhança, constituem lógicas de atenção que se distinguem do mercado ou da regulação do Estado. Constitui-se uma rede de ajuda mútua, capaz de fornecer alternativas para que se enfrentem as condições de pobreza, sendo capaz de romper algumas das barreiras de exclusão social 36,37.

Aquelas mães que puderam contar com uma rede social de suporte reconheceram a sua importância como colaboradora no cuidado dos filhos com deficiência. A participação de vizinhos, companheiros de igreja e familiares também não deixa de atestar a ordenação da rotina e da identidade desta cuidadora, agora foco da atenção e apoio coletivos.
Excepcionalmente foi destacada a participação do marido para além do papel de prover o sustento, e de outros filhos e demais familiares para que ajudassem nos cuidados cotidianos, aliviando a sobrecarga do trabalho. Esta é a realidade para a maior parte das mães que pertencem às camadas populares. Isto vai de encontro à observação de Waldman et al. 26, que detectaram que os pais são muito menos envolvidos que as mães nos cuidados com os filhos, especialmente quando eles têm deficiência.

\section{Considerações finais}

As narrativas das mães de adolescentes com deficiência mental revelam um longo percurso de construção identitária. Partindo do momento de ruptura com o status anterior (mãe ou futura mãe de uma "criança normal") para o de mãe de uma criança com deficiência mental, relatam as vivências iniciais de perplexidade, humilhação, vergonha e, sobretudo, de perda momentânea de referências culturais e psíquicas que ordenassem aquela experiência. A partir daí suas narrativas se atualizam, realizando uma apresentação social de si como mulheres sofridas, abnegadas e corajosas, capazes de se dedicarem incansavelmente ao filho (agora adolescente) e de buscar e cobrar das instituições de saúde e de educação uma atenção que elas considerem (ou mesmo fantasiem) como realmente eficiente.

Denunciam as dificuldades de acesso e de uma atenção de qualidade que seja capaz de proporcionar um atendimento que aprimore as potencialidades das pessoas com deficiência, favorecendo uma maior independência dos filhos e maior inclusão social.

Falam do processo de estigmatização, mas também da capacidade de aglutinarem em torno de si o apoio e a solidariedade de familiares e vizinhos.

Estas mulheres, ao construírem tais narrativas, provavelmente contadas e revisadas periodicamente em seus círculos sociais, confirmam re-significações e atualizam esperanças e expectativas. Revelam um campo de interlocução ainda pouco explorado pelos profissionais e serviços de saúde, e ao projetarem a indefinição do futuro de seus filhos, instauram uma dimensão ética sobre que papel caberá aos agentes e serviços públicos. 


\section{Resumo}

Avanços tecnológicos neonatais têm proporcionado maior sobrevida de bebês com problemas graves de saúde. Muitos terão seu desenvolvimento comprometido (deficiência mental) e demandarão cuidados diferenciados. A família necessita se reorganizar a fim de poder atender às necessidades desta criança. Esta pesquisa buscou identificar os significados construídos por estas mães diante desta situação e os obstáculos que tiveram que enfrentar para alcançar o que consideravam o melhor tratamento para os filhos. Utilizouse como metodologia a análise de narrativas, a partir de referências da antropologia médica e da lingüística. As narrativas revelaram em seus enredos mais típicoso impacto do diagnóstico e a busca de artifícios no cotidiano para adaptar-se aos cuidados com o filho, assim como as dificuldades enfrentadas na rede pública para obterem uma atenção que consideravam adequada. A valorização dos personagens da rede de apoio revelou a importância deste tipo de suporte nestas situações.

Crianças Portadoras de Deficiência; Saúde Mental; Narrativas Pessoais

\section{Referências}

1. Néri M, organizador. Retratos da deficiência no Brasil (PPD). Rio de Janeiro: Fundação Getúlio Vargas/Instituto Brasileiro de Economia; 2003.

2. Amate EA. Adolescentes discapacitados. In: Maddaleno M, Munist MM, Serrano CV, Silber TJ, Ojeda FNS, Yunes J, organizadores. La salud del adolescente y del joven. Washington DC: Organización Panamericana de la Salud; 1996. p. 210-6.

3. Kleinman A. The illness narratives: suffering, healing and the human condition. New York: Basic Books; 1988.

4. Cavalcante FG. Pessoas muito especiais: a construção social do portador da deficiência e a reinvenção da família. Rio de Janeiro: Editora Fiocruz; 2003.

5. Barros MEB, Vieira LFD, Bergamin MP, Scarabelli RS. As articulações saúde e trabalho: relato de experiência em um hospital público, Vitória, Espírito Santo. Cad Saúde Colet (Rio J) 2006; 14:451-68.

6. Helman C. Cultura, saúde e doença. Porto Alegre: Editora Artes Médicas; 1984.

7. Klaus MH, Kennell JH, Klaus PH. Vínculo: construindo as bases para um apego seguro e para a independência. Porto Alegre: Editora Artmed; 2000.

8. Goffman E. A representação do eu na vida cotidiana. Petrópolis: Editora Vozes; 1983.

\section{Colaboradores}

O. M. Bastos realizou o trabalho de campo e a redação do artigo. S. Deslandes participou na orientação metodológica e na redação do artigo.
9. Mishler EG. Narrativa e identidade: a mão dupla do tempo. In: Moita LP, Bastos LC, organizadores. Identidades recortes multi e interdiciplinares. Campinas: Editora Mercado das Letras; 2002. p. 97-122.

10. Linde C. Life stories: the creation of coherence. New York: Oxford University Press; 1993.

11. Garro LC, Mattingly C, editors. Narrative and the natural construction of illness and healing. Berkeley: University of California Press; 2000.

12. Byron-Good BJ. Medicine, rationality, and experience: an anthropological perspective. Cambridge: Cambridge University Press; 1996.

13. Rabelo MCM, Alves PCB, Souza IMA, organizadores. Experiência de doença e narrativa. Rio de Janeiro: Editora Fiocruz; 1999. (Coleção Antropologia e Saúde).

14. Sacks H, Schegloff E, Jefferson G. A simplest systematics for the organization of turn-taking for conversation. Language 1974; 50:696-735.

15. Bastos LC. Contando estórias em contextos espontâneos e institucionais - uma introdução ao estudo das narrativas. Calidoscópio 2005; 3:74-87.

16. Thompson JB. Ideologia e cultura moderna: teoria social crítica na era dos meios de comunicação de massa. Petrópolis: Editora Vozes; 1998. 
17. Labov W. Language in the Inner City. Philadelphia: University of Pensylvania Press; 1972.

18. Vieira AG. Do conceito de estrutura narrativa à sua crítica. Psicol Reflex Crít 2001; 14:599-608.

19. Linde C. Conversational narrative. In: Bright W, editor. International encyclopedia of linguistics. New York: Oxford University Press; 1992. p. 24-7.

20. Gomes R, Mendonça EA. Representação e a experiência da doença: princípios para a pesquisa qualitativa em saúde. In: Minayo MCS, Deslandes SF, organizadoras. Caminhos do pensamento: epistemologia e método. Rio de Janeiro: Editora Fiocruz; 2002. p. 109-32.

21. Alves PC. A experiência da enfermidade: considerações teóricas. Cad Saúde Pública 1993; 9:263-71.

22. Mannoni MA. Criança retardada e a mãe. São Paulo: Editora Martins Fontes; 1991.

23. Paixão AG. Representações sociais e a síndrome de Down: entre o sofrimento e a sua superação. Arq Bras Pediatr 1997; 4:141-6.

24. Klaus MH, Kennell JH. Pais/bebê: a formação do apego. Porto Alegre: Editora Artes Médicas; 1993.

25. Cavalcante FG. Família, subjetividade e linguagem: gramáticas da criança "anormal". Ciênc Saúde Coletiva 2001; 6:125-37.

26. Waldman HB, Swerdloff M, Perlman SP. Children with mental retardation grow older. ASDC J Dent Child 1999; 66:266-72.

27. Aramayo MZ. La familia de la persona con retardo mental: una perspectiva ecologica cultural. Niños (Caracas) 1993; 28:65-94.

28. Associação Brasileira de Reabilitação. Histórico. http://www.fmusicoterapia.hpg.ig.com.br (acessado em 10/Mai/2005).
29. Rocha JSY, Simões BJG, Ortiz PC, Freitas PHM, Matos MPSA, Silva MSP. Avaliação de assistência médica baseada na opinião dos pacientes. Medicina (Ribeirão Preto) 1986; 19:89-98.

30. Mishler EG. Research interviewing: context and narrative. Cambridge: Harvard University Press; 1991.

31. Declaração de Salamanca. Sobre princípios, políticas e práticas na área das necessidades educativas especiais. http://portal.mec.gov.br/seesp/ arquivos/pdf/salamanca.pdf (acessado em 20/ Abr/2007).

32. Vivarta $\mathrm{V}$, coordenador. Mídia e deficiência. Brasília: Agência de Notícias dos Direitos da Infância/ Fundação Banco do Brasil; 2003.

33. Silva EJC. Investigação clínico-epidemiológica em um modelo de educação inclusiva visando ao estudo dos transtornos do desenvolvimento [Tese de Doutorado]. Rio de Janeiro: Instituto Fernandes Figueira, Fundação Oswaldo Cruz; 2002.

34. Griep RH, Chor D, Faerstein E, Lopes C. Apoio social: confiabilidade teste-reteste de escala no estudo pró-saúde. Cad Saúde Pública 2003; 19:625-34.

35. Mance EA. Redes de colaboração solidária: aspectos econômicos-filosóficos: complexidade e libertação. Petrópolis: Editora Vozes; 2002.

36. Glat R, Santos RS, Pletsch MD, Nogueira MLL, Duque MAFT. O método de história de vida na pesquisa em educação especial. Rev Bras Educ Espec 2004; 10:235-50.

37. Martins PH, Fontes B, organizadores. Redes sociais e saúde: novas possibilidades teóricas. Recife: Editora Universitária; 2004.

Recebido em 10/Jul/2007

Versão final reapresentada em 11/Fev/2008

Aprovado em 07/Mar/2008 